\title{
Aline Helg. Libertad e igualdad en el Caribe colombiano, 1770-1835. Medellín: Banco de la República, Universidad Eafit, 2011.
}

DOI: http://dx.doi.org/10.15648/hc.28.2016.10

El libro Libertad e igualdad en el Caribe colombiano de la profesora Aline Helg, muestra la pretensión en Colombia de instaurar una nación blanca. Inicialmente con la aceptación de una nación mestiza en aras de blanqueamiento y cómo en este contexto, las comunidades negras se desdibujaron e invisibilizaron; términos utilizados por la autora para abordar el fenómeno en el Caribe colombiano entre 1770 a 1835 . Buena parte de la tesis acerca de la invisibilización afro en la región, sugiere la autora, fue la ausencia de una identidad negra, que les permitiera tener una acción política colectiva, donde lo racial fuera central, como sí sucedió en Haití.

En este orden de ideas, el libro de Aline Helg, se propone hacer la búsqueda de los orígenes históricos del silencio que Colombia ha mantenido sobre sus raíces afrocaribeñas, enfatizando en el período de transición de la Colonia a la República. Tres preguntas se vuelven centrales en este sentido: ¿Por qué las clases populares afrodescendientes del Caribe colombiano no desafiaron colectivamente a la pequeña élite blanca durante este proceso? ¿Por qué la raza no se convirtió en una categoría organizacional en la región? ¿Por qué la costa del Caribe se integró a la Colombia andina sin hacer valer su identidad afrocaribeña?

Según la autora, los factores que evitaron la formación de una identidad racial en el Caribe colombiano, más o menos similar a la acción colectiva de la revolución haitiana, obedecieron a varias razones. La separación regional, que impidió la comunicación de las comunidades afro del Caribe colombiano con zonas andinas; las formas de integración promovidas a 
finales de la administración colonial como la milicia, la manumisión, el patronazgo, entre otras, que junto a las diferentes estrategias de adaptación de todas las mixturas afrodescendientes, limitaron las posibilidades de una rebelión.

En el primer capítulo la autora aborda el carácter de frontera que tuvo el Caribe colombiano a finales del siglo XVIII. Entendiéndola como aquellos territorios por fuera del control de la Corona y la Iglesia, sitios de asentamiento de población no sujeta a los dispositivos de control social coloniales, denominados rochelas. Albergue de una población negra, india y libres de todos los colores, quienes generalmente se mantuvieron al margen de la doctrina católica, viviendo por fuera de los preceptos cristianos, como es el caso del palenque de San Basilio, que después de varios intentos de sujetarlos bajo el orden hispano, la Corona finalmente les otorgó la autonomía; a pesar que sus costumbres cuestionaban los principios de civilización hispánica. No obstante, las rochelas despertaron siempre constante preocupación por parte de los funcionarios de la Corona, motivo por el cual fueron llevadas a cabo cuatro campañas de reasentamiento durante el periodo Borbónico, con el claro objetivo de nuclear las poblaciones dispersas. Sin embargo, a pesar del discurso de orden y control, tales campañas tenían el interés, según la autora, por parte de los grupos de poder, de acceder a terrenos baldíos ya roturados y al control de mano de obra. Estas políticas de reasentamientos, generaron acciones contestatarias de sus habitantes expresados en: lentitud al trabajar, negación al pago de tributos y comúnmente, la huida a otros territorios para crear nuevas poblaciones al margen de la sociedad hegemónica.

El segundo capítulo responde a los aspectos poblacionales, con base en los censos de 1770 y 1780 y al carácter de frontera de la sociedad caribeña. Según tales empadronamientos, los libres de color constituían la mayoría absoluta de la población del Caribe, excepto en los pueblos de indios, siendo en su mayoría hombres y mujeres de ascendencia africana pura o mezclada. La fuerte presencia de este tipo de población, despertó temores a las autoridades indianas - como el virrey Mendinueta-, por una posible rebelión similar a la haitiana. Sin embargo, según Helg, una rebelión de este tipo habría necesitado de una comunicación permanente entre los 
diferentes poblados, lo que era imposible en el Caribe pues para la época las vías de comunicación eran precarias, inhibiendo parcialmente cualquier posibilidad de relaciones sociales y redes interpersonales que permitieran posibles rebeliones. Además, no existía una interiorización de la cuestión racial, ya que las diferentes acciones contestatarias fueron llevadas a cabo por lo general de manera individual y no colectiva.

De la misma manera señala la debilidad de la Iglesia regional, expresada en la falta de capillas y curas y en una feligresía que gestaba socializaciones alternas al orden moral católico, como los bundes (bailes populares) y el amancebamiento, prueba del grado de autonomía de las rochelas pertenecientes al binterland de las ciudades caribeñas. Lo paradójico es que a pesar del malestar que generaron las reformas borbónicas, aunado a la debilidad del Estado colonial, no se registraron rebeliones de esclavos, como tampoco grandes levantamientos de sectores bajos, aunque sí, muchos rumores de insurrecciones, que no se desarrollaron gracias a los canales que encontraron los esclavos para liberarse e integrarse en la sociedad esclavista, para romperla desde dentro. También por estar limitados por complejas relaciones de patronazgo, que inhibieron una visión clasista y racial entre la población esclava y libre de todos los colores. Lo señalado no implicó la ausencia de resistencias al orden establecido, evidente en el accionar de los bogas, las milicias de pardos y negros, los contrabandistas, entre otros, que en muchos casos fue la expresión de una contracultura, frente al orden colonial.

En el tercer capítulo, aborda el tema de "las ciudades": Cartagena, Mompox, Santa Marta, Valledupar y Riohacha, por ser considerados escenarios importantes de interacción social y primeras referencias de la opinión pública. Lo que primero señala el libro, es que dichas ciudades mantuvieron una fuerte competencia por obtener privilegios, como el control del comercio. Dicha rivalidad, coadyuvó a la carencia de unidad regional y fomentó que el Caribe colombiano terminara por unirse a la zona andina, sin mayores resistencias y plegándose a las directrices de Bogotá. Por otra parte, el conflicto entre ciudades no permeó cuestiones de raza y estatus, pues los diversos mecanismos de integración presentes en la sociedad fueron vías para evadir la cuestión de color por parte de los mulatos pudientes, y 
si bien, las cuestiones raciales y el estatus eran latentes en la cotidianidad de los pueblos arrochelados, tendía a difuminarse por el carácter de la sociedad. En otras palabras, los espacios de integración cristalizados en la sociedad del Caribe colombiano tanto en las zonas urbanas como rurales, hicieron en muchos casos que la raza, por ejemplo, fuera una categoría identitaria vacía parcialmente de sentido.

En este contexto, una de loas principales vías de movilidad social fue el ingreso a la milicia, que permitía a quienes se enlistaban ganancia económica y honores, este último representado en el fuero de guerra que permitía a los mulatos, negros y pardos evitar la justicia ordinaria y acceder a la militar. En otras palabras, eludir la autoridad civil y judicial ordinaria de los alcaldes al esgrimir su condición de milicianos. Además la cédula real de mayo de 1789, conocida como Código Negro, que reglamentó lo referente a la educación, el trato y la ocupación de los esclavos, significó en el Caribe colombiano, un cambio en el discurso de defensa de los esclavos, que se centraba en la ley natural y la caridad cristiana, sin decir con ello que se estuviera pensando en su libertad.

El proceso de independencia en el Caribe colombiano, se inició en 1809, y es el tema del cuarto capítulo, que se enfoca principalmente en la función antagónica de Cartagena autonomista frente a Santa Marta realista, una muestra clara de la falta de unidad en la región. En el caso cartagenero, la lucha patriota no solo fue impulsada por la élite, sino también por sectores sociales bajos, como los artesanos que a la cabeza de Pedro Romero, un zambo, tuvieron una acción protagónica en el proceso independentista del puerto. Como en otras partes de América Hispana, la coyuntura permitió la participación política directa de los subalternos y en algunos casos por vía de las elecciones; por ejemplo la Constitución de Cartagena, reconoció el derecho a los libres de todos los colores, siempre y cuando fueran vecinos, padres de familia, de buena reputación y sin condición servil, lo cual le negaba el derecho al voto a los esclavos.

Si bien el proceso fue liderado por las élites de las localidades, el apoyo popular fue central y en algunos casos, total, como en Valledupar. No obstante, el conflicto en la región se expresó principalmente más por redes de 
familias, como los Toledistas y los Piñeristas, que por otros cauces políticos; los libres de todos los colores y esclavos carecieron de un movimiento propio en el qué ventilar sus objetivos e intereses, y estuvieron sujetos según la autora, a las redes de notables, a las relaciones de patronazgo.

En el quinto capítulo Aline Helg señala cómo la independencia significó algunos espacios de ganancia para los libres de todos los colores y esclavos, pero buena parte de los principios postulados como la noción de igualdad, no fueron llevados a la práctica. La relación con el Estado republicano y los sectores bajos terminó por reducirse al reclutamiento forzado y a los esfuerzos por controlar a una población rural y a los bogas del río Magdalena, a los cuales se les quiso imponer una normatividad que nunca fue efectiva. La Iglesia se debatió entre las condiciones de precariedad y la intención de aumentar su radio de acción, insistiendo en la enseñanza de la fe católica a los niños. Sin embargo, solo se asignaban párrocos a las comunidades que aceptaban el pago del cura y de los derechos parroquiales, lo que fue un obstáculo para su expansión en las áreas rurales acostumbradas a vivir fuera de la pila bautismal, al pago de la congrua y beneficio a los párrocos. En otras palabras el capítulo señala las precariedades de penetración por parte de la autoridad estatal en doble vía, por una parte, la de una verdadera integración de la población de ascendencia afro-descendiente y por otra, de la capacidad de penetración efectiva del Estado a las comunidades dispersas del Caribe.

El sexto capítulo del libro hace referencia al temor de las élites de la instauración de la pardocracia en el Caribe. En este caso se centra en el general Padilla, un oficial pardo, con gran influencia y reconocimiento en los sectores populares de La Heroica y otras localidades de la Costa. Pero por su condición racial fue rechazado por la élite cartagenera, quien terminó acusado de promover una guerra racial, a raíz de un pasquín que el militar escribió en respuesta a la exclusión que tuvo su esposa en un festejo de la élite. El asunto Padilla le permite a la autora sostener la tesis de la instrumentalización del discurso racial y especialmente pardocrático (el supuesto levantamiento de los pardos por el acceso al control político regional o nacional), utilizado por la élite, con el propósito de neutralizar políticamente a quienes habían logrado ascenso social en el nuevo orden 
republicano, y no eran fiables para los grupos de poder tradicionales, quienes veían en ellos una amenaza a su autoridad y al orden establecido. De esta manera, acusar a Padilla de promover una guerra racial era un arma esgrimida para deslegitimarlos y buscar su pérdida política ${ }^{1}$.

A manera de conclusión, este estudio analiza el proceso de instauración del modelo republicano en el Caribe colombiano, teniendo en cuenta las resistencias que se presentaron. Hace hincapié en los procesos que permearon este modelo, argumentando que no estuvo marcado por una suerte maniquea de dominantes-dominados sino que obedeció a una serie de fuerzas de continua relación, que frente a la debilidad del Estado permitieron la formación de una contracultura, materializada en la apatía frente a diferentes instituciones como el matrimonio, en la evasión de impuestos, la negativa de ser reclutados en el ejército, o en las expresiones culturales de asociación en los bailes.

\author{
María Isabel Delgado López \\ Historiadora Universidad del Cauca \\ Miembro del Grupo de Investigación Estado-Nación: \\ Organizaciones e Instituciones \\ azulprofundo1994@gmail.com
}

1 Los planteamientos de Aline Helg encajan con los sostenidos por Jorge Conde Calderón, al considerar que la pardocracia fue una estratagema lingüística usada por los notables del Caribe en la primera mitad del siglo XIX para expresar el miedo a la pardocracia y desprestigiar políticamente a sus adversarios. Jorge Conde Calderón, Buscando la Nación. Ciudadanía, clase y tensión racial en el Caribe colombiano, 1821-1855 (Medellín: La Carreta Histórica, Universidad del Atlántico, 2009), 179-197. 